Article

\title{
Optimizing the Extraction of Polysaccharides from Bletilla ochracea Schltr. Using Response Surface Methodology (RSM) and Evaluating their Antioxidant Activity
}

\author{
Bulei Wang ${ }^{1}$, Yan Xu ${ }^{1}$, Lijun Chen ${ }^{1}$, Guangming Zhao ${ }^{1}$, Zeyuan $\mathrm{Mi}^{1}{ }^{1}$, Dinghao $\mathrm{Lv}^{2}$ and \\ Junfeng Niu ${ }^{1, *}$ \\ 1 National Engineering Laboratory for Resource Development of Endangered Crude Drugs in Northwest \\ China, The Key Laboratory of Medicinal Resources and Natural Pharmaceutical Chemistry, \\ The Ministry of Education, College of Life Sciences, Shaanxi Normal University, Xi'an 710119, China; \\ wangbulei@snnu.edu.cn (B.W.); xuyan530@snnu.edu.cn (Y.X.); 17782674399@163.com (L.C.); \\ zhaoguangminghb@163.com (G.Z.); mizeyuan@snnu.edu.cn (Z.M.) \\ 2 Shanxi Institute of Medicine and Life Sciences, Taiyuan 030006, China; 18636952275@163.com \\ * Correspondence: niujunfeng@snnu.edu.cn; Tel.: +86-29-85310680
}

Received: 24 February 2020; Accepted: 10 March 2020; Published: 16 March 2020

\begin{abstract}
Bletilla ochracea Schltr. polysaccharides (BOP) have a similar structure to Bletilla striata (Thunb.) Reichb.f. (Orchidaceae) polysaccharides (BSP). Therefore, BOP can be considered as a substitute for BSP in the food, pharmaceuticals and cosmetics fields. To the best of our knowledge, little information is available regarding the optimization of extraction and antioxidant activity of BOP. In this study, response surface methodology (RSM) was firstly used for optimizing the extraction parameters of BOP. The results suggested that the optimal conditions included a temperature of $82{ }^{\circ} \mathrm{C}$, a duration of $85 \mathrm{~min}$ and a liquid/material ratio of $30 \mathrm{~mL} / \mathrm{g}$. In these conditions, we received $26.45 \% \pm 0.18 \%$ as the experimental yield. In addition, BOP exhibited strong concentration-dependent antioxidant abilities in vitro. The half-maximal effective concentration $\left(\mathrm{EC}_{50}\right)$ values of $\mathrm{BOP}$ against 1,1-diphenyl-2-picrylhydrazyl (DPPH·), 2,2'-azino-bis (3-ethylbenzothiazoline-6-sulphonate) $\left(\mathrm{ABTS}^{+} \cdot\right)$, hydroxyl $(\cdot \mathrm{OH})$ and superoxide anion $\left(\cdot \mathrm{O}_{2}{ }^{-}\right)$radicals and ferrous ions $\left(\mathrm{Fe}^{2+}\right)$ were determined as $692.16,224.09,542.22,600.53$ and $515.70 \mu \mathrm{g} / \mathrm{mL}$, respectively. In conclusion, our results indicate that $\mathrm{BOP}$ can be a potential natural antioxidant, deserving further investigation.
\end{abstract}

Keywords: Bletilla ochracea Schltr. polysaccharide; response surface methodology (RSM); antioxidant activities

\section{Introduction}

The reactive oxygen species (ROS), including hydrogen peroxide $\left(\mathrm{H}_{2} \mathrm{O}_{2}\right)$, superoxide anion $\left(\cdot \mathrm{O}_{2}{ }^{-}\right)$, hydroxyl $(\cdot \mathrm{OH})$ and peroxyl radicals $(\mathrm{ROO} \cdot)$, are generated in organismal metabolic processes and play important roles in cell signaling, homeostasis and growth regulation at the physiological level [1]. However, excessive ROS can oxidize almost every biomacromolecule (membrane lipid, nucleic acid, and protein), exacerbating many serious diseases, such as diabetes [2], atherosclerosis [3], Alzheimer's disease [4], Parkinson's disease [5] and cancer [6]. Currently, synthetic antioxidants (butylated hydroxyanisole (BHA) and butylated hydroxytoluene (BHT)) are widely used in food, cosmetic and pharmaceutical industries to scavenge the excess ROS, though they might cause many undesirable adverse effects [7]. Thus, efficient and safe antioxidants should be developed imminently to address this problem. 
In recent years, polysaccharides have been applied in the biological fields due to their relatively low toxicity and diverse bioactivities. Especially, the polysaccharide (BSP) from Bletilla striata (Thunb.) Reichb.f. (Orchidaceae) has demonstrated antioxidant [8], immune-regulatory [9] and wound-healing activities [10]. Because of the limited supply of $B$. striata, researchers should explore a new source of similar polysaccharides [11]. Bletilla ochracea Schltr., also named "HuangHuaBaiji" (family: Orchidaceae), has been used as an alternative of B. striata in traditional Chinese medicine (TCM). In a previous study, we have reported that the polysaccharide (BOP) from B. ochracea contains a similar structure to BSP, which is $[\rightarrow(4-\beta$-D-Man- 1$) 4 \rightarrow(4-\beta$-D-Glc-1) $2 \rightarrow 4-2$-O-acetyl- $\beta$-D-Man- $1 \rightarrow$ 4 - $\beta$-D-Man- $1 \rightarrow 4-3-O-$-acetyl- $\beta$-D-Man- $1 \rightarrow 4-2-O-$ acetyl- $\beta$-D-Man- $1 \rightarrow$ ] (Figure 1 ). Meanwhile, BOP also displayed anticancer activity, probably due to its immunostimulatory property [12]. Accordingly, polysaccharides from B. ochracea should be further explored.

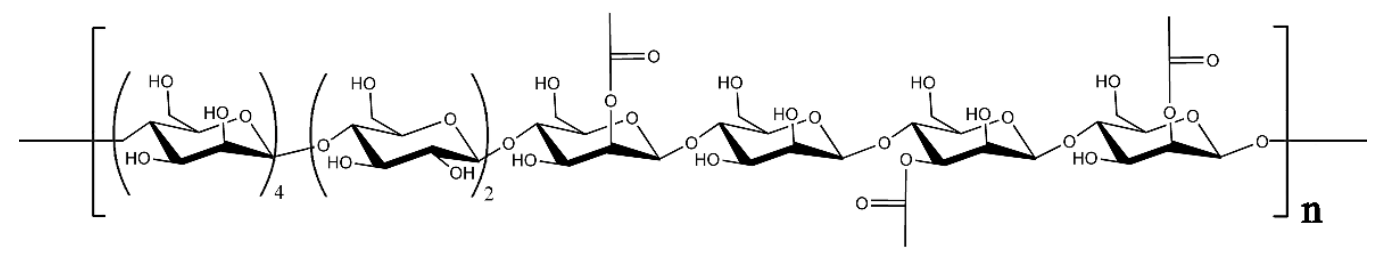

Figure 1. The chemical structures of Bletilla ochracea Schltr. polysaccharide (BOP).

Response surface methodology (RSM), a statistical model for predicting the optimal extraction parameters with high reliability and reproducibility, has been widely applied for gaining maximal yield in the extraction of polysaccharides [13]. For example, Hu et al. optimized the extraction process of the polysaccharide (CAPs) from Camptotheca acuminata fruits (microwave power, $600 \mathrm{~W}$; liquid/solid ratio, $40: 1 \mathrm{~mL} / \mathrm{g}$; time, $14 \mathrm{~min}$; and temperature, $\left.70^{\circ} \mathrm{C}\right)$. Under those conditions, the yield $(8.53 \%)$ was very close to the predicted value $(8.61 \%)$ [14].

In this study, BOP was isolated by extracting with hot water. Box-Behnken design (BBD), a typical RSM, was firstly applied for optimizing the independent variables, including temperature, time and liquid/material. Moreover, the in vitro antioxidant activity was qualitatively and quantitatively evaluated by electron paramagnetic resonance (EPR) technique and radical-scavenging experiments (DPPH., $\mathrm{ABTS}^{+} \cdot, \cdot \mathrm{OH}, \cdot \mathrm{O}_{2}{ }^{-}$and $\mathrm{Fe}^{2+}$ ). In summary, the results are expected to provide the theoretical and technical supports for the further utilization of BOP.

\section{Materials and Methods}

\subsection{Experimental Materials and Chemicals}

The pseudobulbs of B. ochracea were procured from the National Engineering Laboratory for Resource Development of Endangered Chinese Crude Drugs in Northwest of China (Xi'an, Shaanxi Province).

The 2,2-diphenyl-1-picryl-hydrazyl (DPPH), 2,2'-azino-bis (3-ethylbenzothiazoline-6-sulphonate) (ABTS), dihydro-nicotinamide adenine dinucleotide (NADH), nitroblue tetrazolium (NBT), 1-methoxy5-methylphenazinium methyl sulfate (PMS), 5,5-dimethyl-1-pyrroline N-oxide (DMPO) and ferrozine were purchased from Sigma-Aldrich (St. Louis, MO, USA). Petroleum ether $\left(60-90^{\circ} \mathrm{C}\right)$, ethanol, sulfuric acid, phenol, ferrous sulfate and other chemicals were obtained from a local chemical factory (Xi'an, China). All reagents and chemicals used were of analytical reagent (AR) grade.

\subsection{Material Pretreatment and Polysaccharides Extraction}

According to previous reports [15], the tubes of B. ochracea were washed, air-dried, and powdered. The powders were successively preprocessed with petroleum ether $\left(60-90^{\circ} \mathrm{C}\right)$ and $80 \%$ ethanol for depigmenting and delipidating. Then, the polysaccharides were extracted from B. ochracea using hot water. The extracting solution was collected, filtered and precipitated by 4 volumes of ethanol at $4{ }^{\circ} \mathrm{C}$ for $24 \mathrm{~h}$. Finally, the sample was re-dissolved, deproteinized by repeated freeze-thawing for ten 
times [16] and dialyzed against distilled water (exclusion limit 8-14 $\mathrm{kDa}$ ) for $72 \mathrm{~h}$ for further removing the small molecules. The resulting solution was lyophilized and named BOP. The yield of BOP was calculated by the following equation:

$$
\text { Yield }(\%)=\frac{A}{B} \times 100 \%
$$

where $A$ represents the weight of $\mathrm{BOP}$ and $B$ represents the weight of $B$. ochracea powder.

\subsection{Experimental Design}

\subsubsection{Single-Factor Deign}

The single-factor experiment was conducted to determinate preliminary range for extraction parameters, including temperature $\left(50,60,70,80,90^{\circ} \mathrm{C}\right)$, time $(30,60,90,120,150 \mathrm{~min})$, and liquid/material $(10: 1,20: 1,30: 1,40: 1,50: 1 \mathrm{~mL} / \mathrm{g})$. In each experiment, one factor was changed and the others were kept constant. The yield of BOP was a dependent variable.

\subsubsection{Response Surface Methodology (RSM) Design}

Based on the results of the single-factor test, a three-levels-three-factors Box-Behnken design (BBD) was applied to statistically optimize the extraction of the BOP. The independent variables with their levels and BBD experimental design are listed in Tables 1 and 2, respectively. All data, analysis and prediction were performed by Design-Expert software 11.0 (Stat-Ease, Minneapolis, MN, USA).

Table 1. The range and corresponding levels of the independent variables.

\begin{tabular}{cccc}
\hline \multirow{2}{*}{ Variables } & \multicolumn{3}{c}{ Coded Factor Level } \\
\cline { 2 - 4 } & $\mathbf{- 1}$ & $\mathbf{0}$ & $\mathbf{1}$ \\
\hline A, Temperature $\left({ }^{\circ} \mathrm{C}\right)$ & 70 & 80 & 90 \\
B, Time $(\mathrm{min})$ & 60 & 90 & 120 \\
C, Liquid/material $(\mathrm{mL} / \mathrm{g})$ & 20 & 30 & 40 \\
\hline
\end{tabular}

Table 2. The Box-Behnken design with response values for BOP yield.

\begin{tabular}{cccccc}
\hline \multirow{2}{*}{ Run } & $\mathbf{A}\left({ }^{\circ} \mathbf{C}\right)$ & $\mathbf{B}(\mathbf{m i n})$ & $\mathbf{C}(\mathbf{m L} / \mathbf{g})$ & \multicolumn{2}{c}{ BOP Yield (\%) } \\
\cline { 5 - 6 } & & & & Experimental & Predicted \\
\hline 1 & -1 & -1 & 0 & 23.54 & 23.30 \\
2 & 0 & 1 & -1 & 24.08 & 23.93 \\
3 & -1 & 0 & 1 & 23.57 & 23.66 \\
4 & 0 & 0 & 0 & 26.75 & 26.62 \\
5 & -1 & 0 & -1 & 23.67 & 23.77 \\
6 & -1 & 1 & 0 & 23.96 & 24.01 \\
7 & 0 & 0 & 0 & 26.49 & 26.62 \\
8 & 0 & -1 & -1 & 24.73 & 24.87 \\
9 & 1 & 0 & -1 & 24.46 & 24.37 \\
10 & 1 & -1 & 0 & 25.36 & 25.31 \\
11 & 0 & 0 & 0 & 26.82 & 26.62 \\
12 & 0 & -1 & 1 & 24.36 & 24.51 \\
13 & 0 & 0 & 0 & 26.54 & 26.62 \\
14 & 0 & 1 & 1 & 24.47 & 24.33 \\
15 & 1 & 1 & 0 & 23.25 & 23.49 \\
16 & 0 & 0 & 0 & 26.48 & 26.62 \\
17 & 1 & 0 & 1 & 24.63 & 24.53 \\
\hline
\end{tabular}




\subsection{In Vitro Antioxidant Activity of BOP}

\subsubsection{DPPH Radical Scavenging Activity}

According to a reported method [17], $100 \mu \mathrm{L}$ of different concentrations $(0-2 \mathrm{mg} / \mathrm{mL})$ of BOP and vitamin $\mathrm{C}\left(\mathrm{V}_{\mathrm{C}}\right)$ were mixed with $100 \mu \mathrm{L}$ of $\mathrm{DPPH}$-ethanol solution $(0.3 \mathrm{mM})$ at $37^{\circ} \mathrm{C}$ for $30 \mathrm{~min}$ in the dark. Subsequently, the absorbance was measured at $517 \mathrm{~nm}$. The DPPH. scavenging rate was calculated with the following equation:

$$
P P H \text { radical scavenging rate }(\%)=\left(1-\frac{A_{1}-A_{2}}{A_{0}}\right) \times 100 \%
$$

where $A_{0}$ is the absorbance of the mixture without samples (replaced by distilled water), $A_{1}$ is the absorbance of the reaction solutions and $A_{2}$ is only the absorbance of the BOP.

\subsubsection{ABTS radical Scavenging Activity}

According to a reported method [18], ABTS solution (7.2 mM) and $\mathrm{K}_{2} \mathrm{~S}_{2} \mathrm{O}_{8}$ solution (in a 1:1 ratio) were co-incubated at room temperature in the dark for $24 \mathrm{~h}$ to produce $\mathrm{ABTS}^{+}$. The resulting solution was diluted to obtain an absorbance of 0.7 at $734 \mathrm{~nm}$. Then, $50 \mu \mathrm{L}$ of different concentrations $(0-2 \mathrm{mg} / \mathrm{mL})$ of BOP and $\mathrm{V}_{\mathrm{C}}$ were mixed with $150 \mu \mathrm{L}$ of the $\mathrm{ABTS}^{+}$. solution and placed in the dark for $5 \mathrm{~min}$. Subsequently, the absorbances of the reaction solutions were measured at $734 \mathrm{~nm}$. The $\mathrm{ABTS}^{+}$. scavenging rate was calculated with the following equation:

$$
\text { ABTS radical scavenging rate }(\%)=\left(1-\frac{A_{1}-A_{2}}{A_{0}}\right) \times 100 \%
$$

where $A_{0}$ is the absorbance of the mixture without samples (replaced by distilled water), $A_{1}$ is the absorbance of the reaction solutions and $A_{2}$ is only the absorbance of the BOP.

\subsubsection{Ferrous Chelating Activity}

According to a reported method [19], $100 \mu \mathrm{L}$ of different concentrations $(0-2 \mathrm{mg} / \mathrm{mL})$ of BOP and ethylenediaminetetraacetic acid disodium salt (EDTA-2Na) were mixed with $50 \mu \mathrm{L}$ of $\mathrm{FeSO}_{4}(0.125 \mathrm{mM})$ and $50 \mu \mathrm{L}$ of ferrozine $(1 \mathrm{mM})$ and incubated for $10 \mathrm{~min}$ at $37^{\circ} \mathrm{C}$. Subsequently, the absorbance was measured at $562 \mathrm{~nm}$. The $\mathrm{Fe}^{2+}$ chelating rate was calculated with the following equation:

$$
F e^{2+} \text { chelating rate }(\%)=\left(1-\frac{A_{1}-A_{2}}{A_{0}}\right) \times 100 \%
$$

where $A_{0}$ is the absorbance of the mixture without the samples (replaced by distilled water), $A_{1}$ is the absorbance of the reaction solutions and $A_{2}$ is only the absorbance of the BOP.

\subsubsection{Hydroxyl Radical Scavenging Activity}

According to a reported method [20], $50 \mu \mathrm{L}$ of different concentrations $(0-2 \mathrm{mg} / \mathrm{mL})$ of BOP and $\mathrm{V}_{\mathrm{C}}$ were mixed with $50 \mu \mathrm{L}$ of sodium salicylate $(9 \mathrm{mM}), 0.05 \mathrm{~mL}$ of $\mathrm{FeSO}_{4}(9 \mathrm{mM})$ and $0.35 \mathrm{~mL}$ of $\mathrm{H}_{2} \mathrm{O}_{2}$ $(0.025 \%)$ and incubated for $10 \mathrm{~min}$ at $37^{\circ} \mathrm{C}$. Subsequently, the absorbance was measured at $562 \mathrm{~nm}$. The $\cdot \mathrm{OH}$ scavenging rate was calculated with the following equation:

$$
\text { Hydroxyl radical scavenging rate }(\%)=\left(1-\frac{A_{1}-A_{2}}{A_{0}}\right) \times 100
$$

where $A_{0}$ is the absorbance of the mixture without the samples (replaced by distilled water), $A_{1}$ is the absorbance of the reaction solutions and $A_{2}$ is only the absorbance of the BOP. 
For spin-trapping $\cdot \mathrm{OH}$ experiments by electron paramagnetic resonance (EPR, JES-FA series, Japan), $100 \mu \mathrm{L}$ of BOP $(2.0 \mathrm{mg} / \mathrm{mL})$ and deionized water were mixed with the fresh mixture of $\mathrm{FeSO}_{4}$ $(100 \mu \mathrm{L}, 9 \mathrm{mM})$ and the spin traps DMPO $(100 \mu \mathrm{L}, 50 \mathrm{mM})$. Then, $\mathrm{H}_{2} \mathrm{O}_{2}$ was added to generate hydroxyl radicals. The reaction mixtures were immediately transferred to the EPR tube and fitted into the tester. The EPR signal was detected at $20^{\circ} \mathrm{C}$. The settings of the spectrometer were as follows: microwave power, $20 \mathrm{~mW}$; modulation frequency, $100 \mathrm{kHz}$; modulation amplitude, $1.0 \mathrm{G}$.

\subsubsection{Superoxide Anion Radical Scavenging Activity}

According to a reported method [21], $50 \mu \mathrm{L}$ of different concentrations $(0-2 \mathrm{mg} / \mathrm{mL})$ of BOP and $\mathrm{V}_{\mathrm{C}}$ were mixed with $0.05 \mathrm{~mL}$ of NADH $(470 \mu \mathrm{M}), 0.05 \mathrm{~mL}$ of NBT $(156 \mu \mathrm{M})$ and $0.05 \mathrm{~mL}$ of PMS $(60 \mu \mathrm{M})$ and incubated for $5 \mathrm{~min}$. Subsequently, the absorbance was measured at $562 \mathrm{~nm}$. The $\cdot \mathrm{O}_{2}{ }^{-}$ scavenging rate was calculated with the following equation:

$$
\text { Superoxide anion radical scavenging rate }(\%)=\left(1-\frac{A_{1}-A_{2}}{A_{0}}\right) \times 100 \%
$$

where $A_{0}$ is the absorbance of the mixture without the samples (replaced by distilled water), $A_{1}$ is the absorbance of the reaction solutions and $A_{2}$ is only the absorbance of the BOP.

For spin-trapping $\cdot \mathrm{O}_{2}{ }^{-}$experiments, $100 \mu \mathrm{L}$ of BOP $(2.0 \mathrm{mg} / \mathrm{mL})$ and deionized water were mixed with a fresh solution of NADH $(100 \mu \mathrm{L}, 156 \mathrm{M})$ and the spin traps DMPO $(100 \mu \mathrm{L}, 50 \mathrm{mM})$, separately. Then, the PMS $(50 \mu \mathrm{L}, 60 \mu \mathrm{M})$ was added to initiate the generation of superoxide anion radicals. The reaction mixtures were immediately transferred to the EPR tube and fitted into the tester. The EPR signal was recorded at $20^{\circ} \mathrm{C}$. The settings of the spectrometer were as follows: microwave power, $20 \mathrm{~mW}$; modulation frequency, $100 \mathrm{kHz}$; modulation amplitude, $1.0 \mathrm{G}$.

\subsection{Statistical Analysis}

All experiments were performed in triplicate; the results are presented as the means \pm standard deviation (SD). One-way analysis of variance was used for the statistical comparisons (IBM SPSS Statistics 23). The differences between the means were considered statistically significant at $P<0.05$.

\section{Results}

\subsection{Single-Factor Experiments for BOP Extraction}

The influence of temperature on the yield of BOP is illustrated in Figure 2A. When time and the ration of liquid/material were fixed at $90 \mathrm{~min}$ and $30: 1 \mathrm{~mL} / \mathrm{g}$, respectively, the yield increased with the temperature $\left(50-80{ }^{\circ} \mathrm{C}\right)$ and reached the maximum value at $80{ }^{\circ} \mathrm{C}$. However, the yield showed a decreasing tendency at the range of $80-90^{\circ} \mathrm{C}$. Thus, 70,80 and $90^{\circ} \mathrm{C}$ were applied in further experiments.
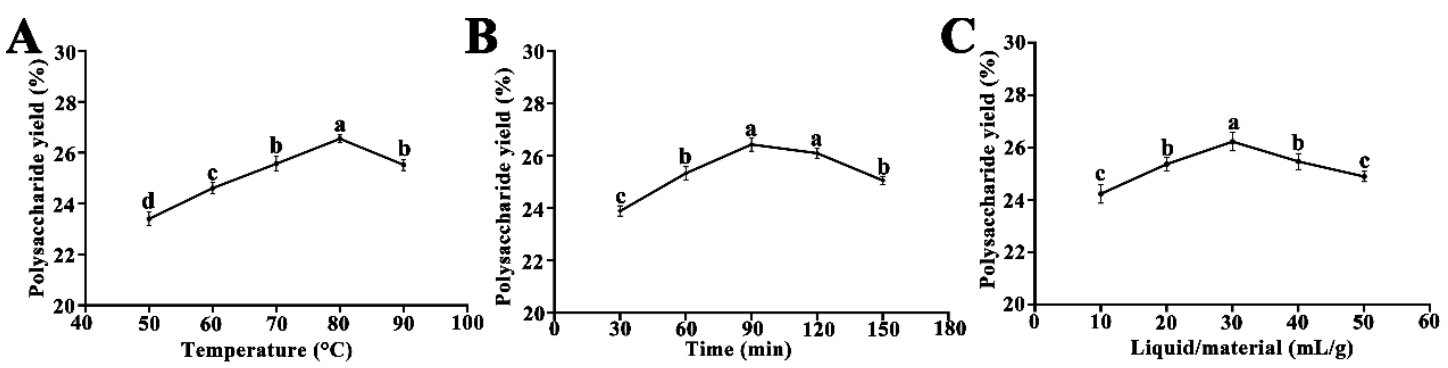

Figure 2. Effects of different temperatures (A), times (B) and liquid/material ratios (C) on the yield of the BOP.

The influence of time on the yield of BOP is illustrated in Figure 2B. When the temperature and the ratio of liquid/material were fixed at $80^{\circ} \mathrm{C}$ min and $30: 1 \mathrm{~mL} / \mathrm{g}$, respectively, the yield increased with 
time (30-90 $\mathrm{min}$ ) and reached the maximum value in $90 \mathrm{~min}$. However, the yield showed a decreasing tendency during 90-150 min. Thus, 80, 90 and $120 \mathrm{~min}$ were applied in further experiments.

The influence of liquid/material on the yield of BOP is illustrated in Figure 2C. When temperature and time were fixed at $80{ }^{\circ} \mathrm{C} \mathrm{min}$ and $90 \mathrm{~min}$, respectively, the yield increased when the ration of liquid/material (10-30 mL/g) was increased and reached the maximum value for $30 \mathrm{~mL} / \mathrm{g}$. However, the yield showed a decreasing tendency for $30-50 \mathrm{~mL} / \mathrm{g}$. Thus, 20,30 and $40 \mathrm{~mL} / \mathrm{g}$ were applied in further experiments.

\subsection{Model Fitting and Statistical Analysis}

The predicted and experimental yields of $\mathrm{BBD}$, including 17 experimental runs, are summarized in Table 2. The extraction yields of BOP ranged from $23.25 \%$ to $26.82 \%$ with a different combination of the independent parameters. Based on multiple regression analysis of the experimental data, a second-order polynomial equation was established to correlate the yield of BOP and the test variables.

$$
\begin{gathered}
Y=26.26+0.37 \times A-0.28 \times B+0.011 \times C-0.63 \times A B+0.067 \times A C+ \\
0.19 \times B C-1.46 \times A^{2}-1.13 \times B^{2}-1.08 \times C^{2}
\end{gathered}
$$

where $Y, B, C$ and $D$ represented the yield of BOP, temperature, time and the ratio of liquid/material, respectively.

Additionally, the analysis of variance (ANOVA) for the model is presented in Table 3. A high F-value (57.98) and a low $P$-value $(<0.0001)$ indicated the statistical significance of the model. The lack of fit of F-value (3.13) and $P$-value (0.1496) implied excellent agreement between the experimental and predicted values. Meanwhile, the coefficient of determination $\left(R^{2}=0.9868\right)$ suggested that only $1.32 \%$ of total variables could not be explained by the model. Moreover, the high adjusted (adj) and low coefficient variation $(\mathrm{CV}=0.8)$ also supported the above conclusion that we successfully developed a model with high precision, reliability, and reproducibility for optimizing the yield of the BOP. Accordingly, two linear terms (A and $\mathrm{B})$, one interaction term $(\mathrm{AB})$ and all quadratic terms $\left(\mathrm{A}^{2}, \mathrm{~B}^{2}\right.$ and $\mathrm{C}^{2}$ ) exhibited that the extraction rate could be highly significant [22].

\begin{tabular}{|c|c|c|c|c|c|}
\hline Source & Sum of Squares & $\mathrm{df}^{\mathrm{a}}$ & Mean Square & $F$-Value & $P$-Value \\
\hline Model & 24.88 & 9 & 2.76 & 57.98 & $<0.0001^{* *}$ \\
\hline A & 1.10 & 1 & 1.10 & 22.97 & $0.0020 * *$ \\
\hline $\mathrm{B}$ & 0.62 & 1 & 0.62 & 13.04 & $0.0086^{* *}$ \\
\hline $\mathrm{C}$ & $1.012 \times 10^{-3}$ & 1 & $1.012 \times 10^{-3}$ & 0.021 & $0.8883^{\mathrm{ns}}$ \\
\hline $\mathrm{AB}$ & 1.60 & 1 & 1.60 & 33.56 & $0.0007^{* *}$ \\
\hline $\mathrm{AC}$ & 0.018 & 1 & 0.018 & 0.38 & $0.5560^{\mathrm{ns}}$ \\
\hline $\mathrm{BC}$ & 0.14 & 1 & 0.14 & 3.03 & $0.1254^{\mathrm{ns}}$ \\
\hline$A^{2}$ & 8.95 & 1 & 8.95 & 187.70 & $<0.0001^{* *}$ \\
\hline $\mathrm{B}^{2}$ & 5.38 & 1 & 5.38 & 112.85 & $<0.0001 * *$ \\
\hline$C^{2}$ & 4.87 & 1 & 4.87 & 102.14 & $<0.0001^{* *}$ \\
\hline Residual & 0.33 & 7 & 0.048 & & \\
\hline Lack of fit & 0.23 & 3 & 0.078 & & \\
\hline Pure error & 0.100 & 4 & 0.025 & 3.13 & $0.1496^{\mathrm{ns}}$ \\
\hline Correlation total & 25.22 & 16 & & & \\
\hline$R^{2}=0.9868$ & $\operatorname{Adj} \mathrm{R}^{2}=0.9697$ & & & C.V. $\%=0.88$ & \\
\hline
\end{tabular}

Table 3. ANOVA for the response surface quadratic model.

${ }^{\text {a }}$ Degree of freedom. ${ }^{* *}$ Highly significant. ${ }^{\text {ns }}$ Not significant.

\subsection{Response Surface Analysis and Validation Experiments}

The 3D response surface and 2D contour plots of the model were constructed to especially investigate the correlation between the response $\mathrm{Y}$ and three independent variables (Figure 3). The shapes of the contour plots, such as elliptical or circular, indicated whether the variable mutual 
interactions were significant or not [23]. Obviously, only the interaction of temperature and time was significant for the yield of BOP by observing the contours of the graphs and the density, which were in agreement with the ANOVA results.
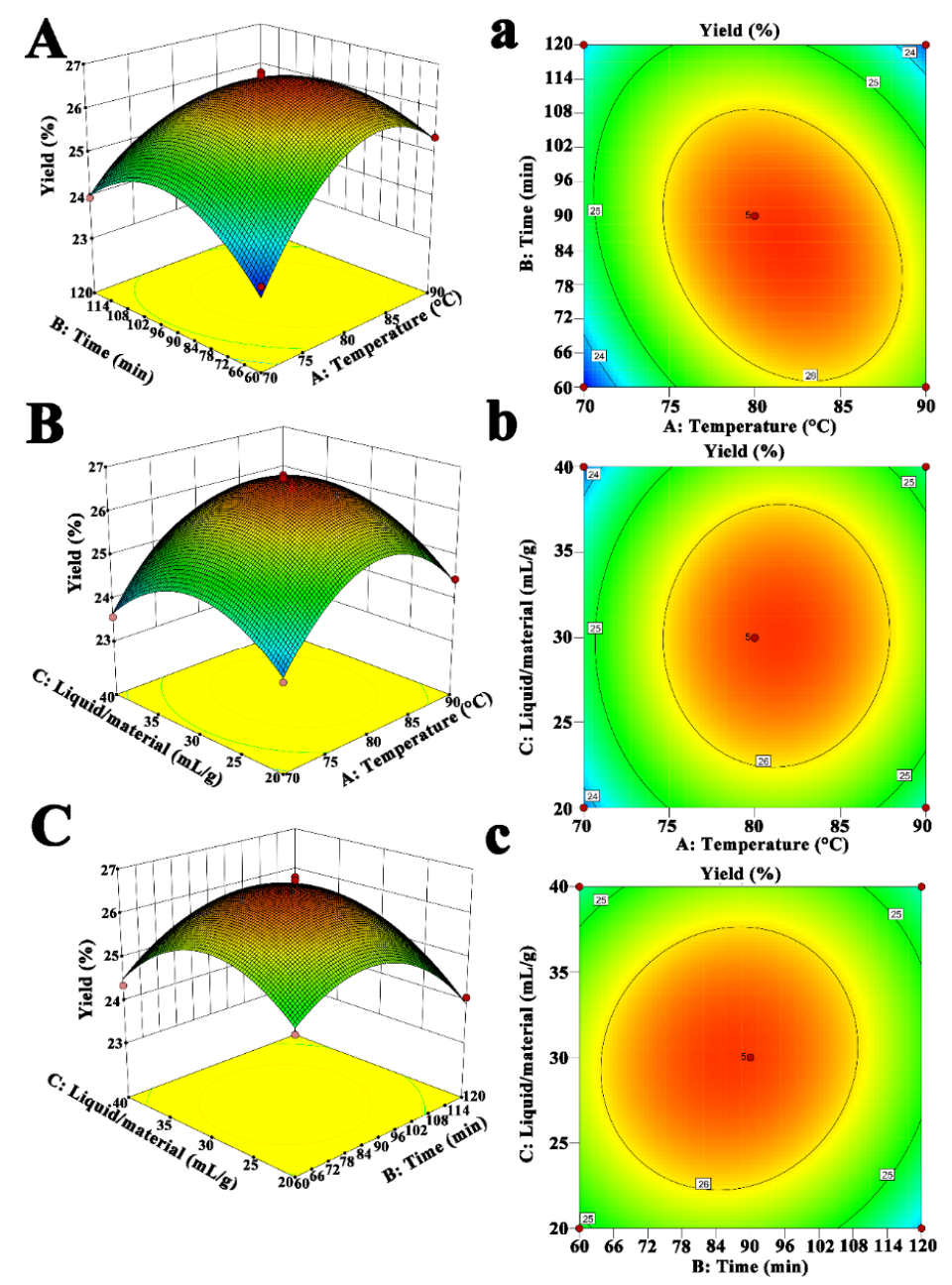

Figure 3. Response surface plots and contour plots showing the effect of the temperature $(\mathbf{A}, \mathbf{a})$, time $(\mathbf{B}, \mathbf{b})$ and liquid/material ratio $(\mathbf{C}, \mathbf{c})$ on the yield of the BOP.

Through solving Equation (1), the optimized extractions were obtained as: temperature of $81.64{ }^{\circ} \mathrm{C}$, time of $84.96 \mathrm{~min}$ and liquid/material ratio of $29.95 \mathrm{~mL} / \mathrm{g}$; the maximum yield of BOP was predicted as $26.6698 \%$. Considering the practicality, we adjusted the extraction parameters to the temperature of $82{ }^{\circ} \mathrm{C}$, duration of $85 \mathrm{~min}$ and ratio of liquid/material of $30 \mathrm{~mL} / \mathrm{g}$, and we obtained the experimental yield as $26.45 \% \pm 0.18 \%$, which was close the predicted value, demonstrating that the model could be used for optimizing the extraction of BOP.

\subsection{In Vitro Antioxidant Activity of BOP}

\subsubsection{DPPH, ABTS Radicals Scavenging and $\mathrm{Fe}^{2+}$ Chelating Abilities of the BOP}

The results of DPPH radical scavenging experiments are illustrated in Figure 4A. Clearly, BOP exhibited excellent DPPH. scavenging rate concentration-dependently from 62.5 to $2000 \mu \mathrm{g} / \mathrm{mL}$. At the maximum concentration $(2000 \mu \mathrm{g} / \mathrm{mL})$, the scavenging ability was $78.06 \%$, which was lower than that of the positive control $\left(\mathrm{V}_{\mathrm{C}}, 95.94 \%\right)$. Additionally, the half-effective concentration $\left(\mathrm{EC}_{50}\right)$ of $\mathrm{BOP}$ was calculated as $692.16 \mu \mathrm{g} / \mathrm{mL}$. 

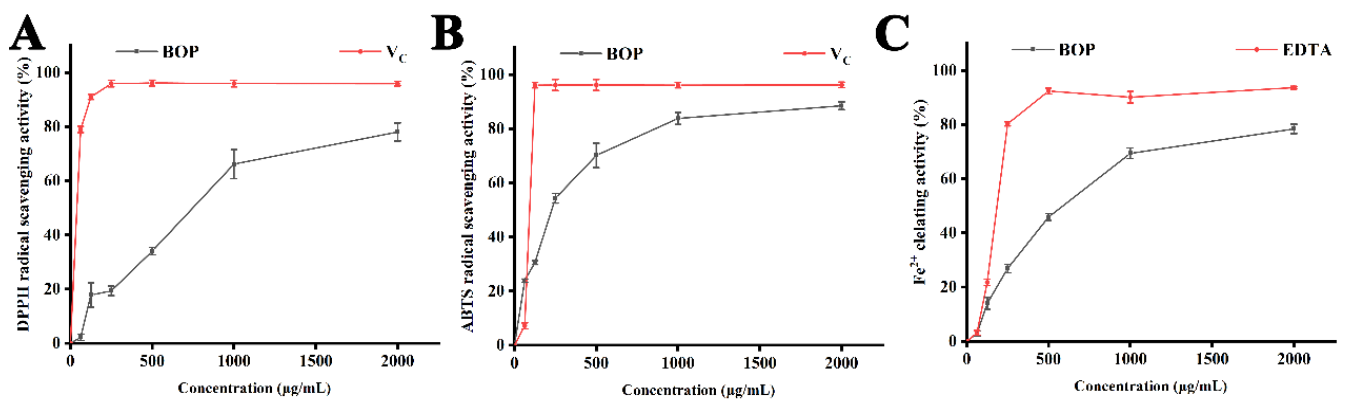

Figure 4. DPPH. (A) and $\mathrm{ABTS}^{+} \cdot(\mathrm{B})$ scavenging and $\mathrm{Fe}^{2+}(\mathbf{C})$ chelating activities of the BOP.

The results of ABTS radical scavenging experiments are illustrated in Figure 4B. Obviously, BOP exhibited outstanding $\mathrm{ABTS}^{+}$. scavenging rate concentration-dependently from 62.5 to $2000 \mu \mathrm{g} / \mathrm{mL}$. At the maximum concentration $(2000 \mu \mathrm{g} / \mathrm{mL})$, the scavenging ability was $88.50 \%$, which was similar to $\mathrm{V}_{\mathrm{C}}(96.19 \%)$. Additionally, the $\mathrm{EC}_{50}$ of BOP was calculated as $224.09 \mu \mathrm{g} / \mathrm{mL}$.

The results of ferrous ion chelating experiments are illustrated in Figure 4C. Evidently, BOP exhibited remarkable $\mathrm{Fe}^{2+}$ chelating rate concentration-dependently from 62.5 to $2000 \mu \mathrm{g} / \mathrm{mL}$. At the maximum concentration $(2000 \mu \mathrm{g} / \mathrm{mL})$, the chelating ability was $89.94 \%$, which was similar than the positive control (EDTA-2Na, 94.03\%). Additionally, the $\mathrm{EC}_{50}$ of BOP was calculated as $515.70 \mu \mathrm{g} / \mathrm{mL}$.

\subsubsection{Hydroxyl and Superoxide Anion Scavenging Effects of BOP and EPR Detection}

The results of the hydroxyl radical scavenging experiment are illustrated in Figure 5A. Apparently, BOP exhibited an excellent $\cdot \mathrm{OH}$ scavenging rate concentration-dependently from 62.5 to $2000 \mu \mathrm{g} / \mathrm{mL}$. At the maximum concentration $(2000 \mu \mathrm{g} / \mathrm{mL})$, the chelating ability was $82.89 \%$, which was lower than the positive control $\left(\mathrm{V}_{\mathrm{C}} 91.93 \%\right)$. Additionally, the $\mathrm{EC}_{50}$ of $\mathrm{BOP}$ was calculated as $542.22 \mu \mathrm{g} / \mathrm{mL}$. Furthermore, we used EPR technology to qualitatively determine the $\mathrm{OH}$ radical scavenging effect of the BOP. In Figure 5a, the signal acquisition by the control group was very high and obvious, while the signal becomes relatively lower and weaker in the BOP group, indicating that the polysaccharide could effectively eliminate $\cdot \mathrm{OH}$ in vitro, which agreed with the aforementioned quantitative results.
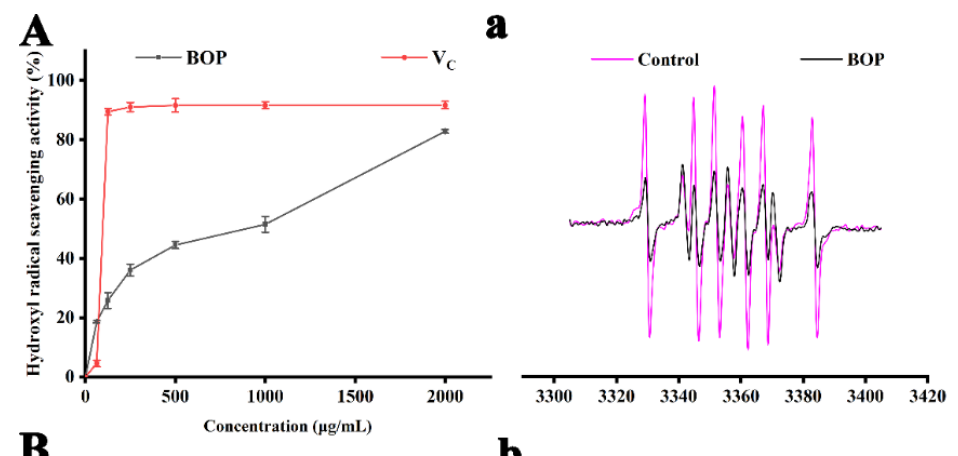

\section{B}

b

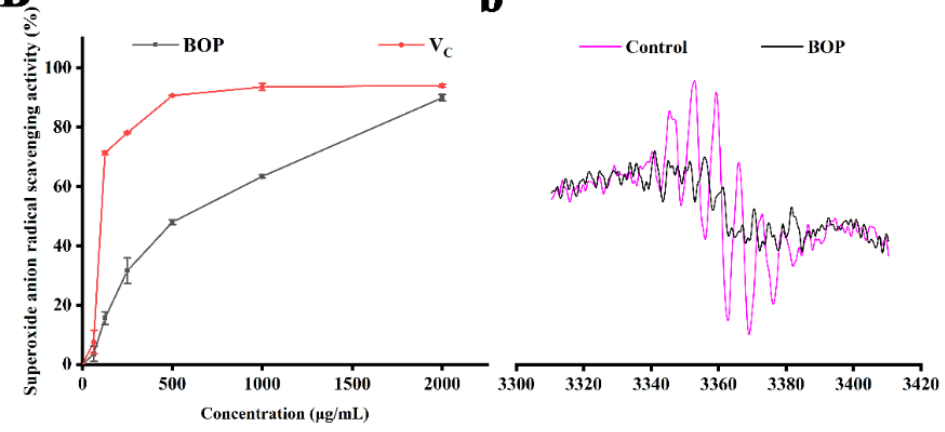

Figure 5. The radical scavenging abilities and EPR spectra of the BOP. (A,a) hydroxyl radical; $(\mathbf{B}, \mathbf{b})$ superoxide anion radical. 
The results of the superoxide anion radical scavenging experiment are illustrated in Figure 5B. Apparently, BOP exhibited an excellent $\cdot \mathrm{O}_{2}{ }^{-}$scavenging rate concentration-dependently from 62.5 to $2000 \mu \mathrm{g} / \mathrm{mL}$. At the maximum concentration $(2000 \mu \mathrm{g} / \mathrm{mL})$, the chelating ability was $89.94 \%$, which was close than positive control of $94.03 \%$. Additionally, the $\mathrm{EC}_{50}$ of BOP was calculated as $600.53 \mu \mathrm{g} / \mathrm{mL}$. Furthermore, we used EPR technology to qualitatively determine the $\cdot \mathrm{O}_{2}{ }^{-}$radical scavenging effect of the BOP. In Figure $5 b$, the signal acquisition by the control group was very high and significant, while the signal becomes relatively lower and weaker in the BOP group, indicating that the polysaccharide could effectively eliminate $\cdot \mathrm{O}_{2}{ }^{-}$in vitro, which agreed with the aforementioned quantitative results.

\section{Discussion}

Traditionally, most of the Chinese herbs were extracted by decoction, and polysaccharide is the main component of the aqueous extracts of these herbs. Modern pharmacological studies suggest that polysaccharides possess multiple bioactivities, including antidiabetic [24], anticancer [25], antioxidant [26] and anti-inflammatory [27] effects. Particularly, antioxidants have various promising applications for food preservation and pharmacotherapy.

Hot water extraction (HWE), a conventional and convenient method, is widely applied to extract the polysaccharides from different herbs. During extraction, the temperature, time and ratio of liquid/material can significantly influence the yield. Su et al. stated that elevating the temperature could accelerate the dissolution and diffusion of polysaccharide, thus increasing the yield [28]. However, other reports indicated that the extremely high temperature can degrade the polysaccharide, thus decreasing the yield (Figure 2A) [29]. Analogically, the bioactive compounds were completely dissolved during a reasonable extraction period, whereas a long extraction period could hydrolyze the polysaccharides [30]. Thus, when the extraction time was lengthened, the yield of BOP increased at first, then reduced gradually after reaching the peak value (Figure 2B). Furthermore, the ratio of liquid/material was a crucial factor for polysaccharide's extraction. Generally, a low ratio of liquid/material suggests that the volume of water was too low for extracting the polysaccharide. Sufficient liquid/material implied greater concentration difference between the plant cell and exterior water, accelerating the polysaccharide's diffusion from cell to external water. In contrast, with the saturation of water, the mass transfer rate changed negatively, and a high volume of liquid would result in the wastage of water and polysaccharide in the subsequent procedure (Figure 2C) [31]. Compared to the traditional orthogonal testing, RSM exhibited many advantages, such as establishing a high precision regression equation and describing the interactions between several factors in detail. In this study, the extraction conditions of BOP were firstly optimized by RSM for achieving the maximal yield (26.45\%).

Highly unstable free radicals are qualitatively detected by EPR technology. We used DMPO as traps for generating the signal intensity to indicate the existence of free radical; a high corresponding signal peak indicated a higher concentration of the free radical [32]. DPPH., a stable reactive nitrogen species (RNS), can become a DPPH-H molecule by receiving a hydrogen atom [33]. Thus, the DPPH. scavenging experiment can assess the antioxidant ability of polysaccharide (Figure 4A). ABTS was oxidized by $\mathrm{K}_{2} \mathrm{~S}_{2} \mathrm{O}_{8}$, generating green $\mathrm{ABTS}^{+}$. Antioxidants reduced the $\mathrm{ABTS}^{+}$., and the system became blue in color [34]. The change in color to blue/green reveals that the polysaccharide possesses an antioxidant effect (Figure 4B). However, both DPPH. and $\mathrm{ABTS}^{+}$. are nonphysiological radicals. Therefore, a more physiological-radical scavenging test should be conducted for comprehensively evaluating the antioxidant ability of the sample. Specifically, OH, one of the most harmful ROS, can be produced by Fenton reaction $\left(\mathrm{Fe}^{2+}+\mathrm{H}_{2} \mathrm{O}_{2}=\mathrm{Fe}^{3+}+\mathrm{OH}^{-}+\cdot \mathrm{OH}\right)$. Meanwhile, $\cdot \mathrm{O}_{2}^{-}$, an initial free radical, forms other stronger ROS, including singlet oxygen and $\mathrm{H}_{2} \mathrm{O}_{2}$.

In a previous study, we determined the preliminary structure of BOP, which is [ $\rightarrow(4-\beta$-D-Man- 1$)$ $4 \rightarrow(4-\beta$-D-Glc- 1$) 2 \rightarrow 4-2-\mathrm{O}$-acetyl- $\beta$-D-Man- $1 \rightarrow 4-\beta$-D-Man- $1 \rightarrow 4-3$-O-acetyl- $\beta$-D-Man- $1 \rightarrow 4-2-\mathrm{O}$-acetyl$\beta$-D-Man- $\rightarrow$ - [12]. Thus, BOP, with many active hydroxyl groups, can not only scavenge free radicals directly but also reduce the formation of free radicals by metal chelation [35]. For example, $\cdot \mathrm{OH}$ can form water by combining with the hydrogen atoms in the hydrocarbon chain of BOP (Figure 5A,a). 
Meanwhile, BOP exhibited an outstanding $\mathrm{Fe}^{2+}$ chelating effect, inhibited the Fenton reaction and then decreased the production of $\cdot \mathrm{OH}$ (Figure $4 \mathrm{C}$ ). Additionally, $\cdot \mathrm{O}_{2}{ }^{-}$can be scavenged by BOP via redox reaction (Figure $5 \mathrm{~B}, \mathrm{a}$ ). Qu et al. extracted the BSP by infrared-assisted extraction (IRAE) and assessed their antioxidant activity in vitro. In the same concentration of sample, BOP showed stronger abilities for scavenging DPPH., $\cdot \mathrm{OH}$ and $\cdot \mathrm{O}_{2}{ }^{-}$and chelating $\mathrm{Fe}^{2+}$ than BSP [8]. Generally, the in vitro antioxidant activity of polysaccharides might be affected by multiple factors, such as molecular weight, configuration and even factors associated with the selected antioxidant evaluation system [36]. Thus, BOP exhibited better antioxidative capacity than BSP and should be developed as a potential natural antioxidant.

\section{Conclusions}

In the present study, an optimal extraction of BOP was verified by RSM with BBD. The optimum conditions were demonstrated as: temperature of $82^{\circ} \mathrm{C}$; time of $85 \mathrm{~min}$; and liquid/material ratio of $30 \mathrm{~mL} / \mathrm{g}$. A practical yield of $26.45 \%$ was obtained, corresponding to the predicted value $(26.6698 \%)$. Meanwhile, BOP exhibited outstanding antioxidant activity in vitro, such as scavenging of DPPH., $\mathrm{ABTS}^{+} ., \cdot \mathrm{OH}$ and $\cdot \mathrm{O}_{2}{ }^{-}$and chelating of $\mathrm{Fe}^{2+}$. Finally, our findings demonstrated that BOP could be considered as a potential antioxidant ingredient for applications in food, medical and cosmetics industries. Further investigation about the in vivo antioxidant ability of BOP is in progress.

Author Contributions: B.W. wrote the manuscript. B.W. and Y.X. preformed the experiments. L.C. and G.Z. analyzed the data. Z.M. and D.L. contributed reagents/materials tools. J.N. designed the experiments and revised the manuscript. All authors have read and agreed to the published version of the manuscript.

Funding: This research was funded by National Natural Science Foundation of China $(81571834,31670299)$, the Fundamental Research Funds for the Central Universities (GK201906008, 2019CSLY028), the National Key Technologies R \& D Program for Modernization of Traditional Chinese Medicine (2017YFC1701300, 2017YFC1700706), and the APC was funded by the Key R\&D Program of Shaanxi Province (2019SF-307).

Conflicts of Interest: The authors declare no conflict of interest.

\section{References}

1. Su, Y.; Li, L. Structural characterization and antioxidant activity of polysaccharide from four auriculariales. Carbohydr. Polym. 2020, 229, 115407. [CrossRef] [PubMed]

2. Forbes, J.M.; Coughlan, M.T.; Cooper, M.E. Oxidative stress as a major culprit in kidney disease in diabetes. Diabetes 2008, 57, 1446-1454. [CrossRef] [PubMed]

3. Yuan, T.; Yang, T.; Chen, H.; Fu, D.; Hu, Y.; Wang, J.; Yuan, Q.; Yu, H.; Xu, W.; Xie, X. New insights into oxidative stress and inflammation during diabetes mellitus-accelerated atherosclerosis. Redox. Biol. 2019, 20, 247-260. [CrossRef] [PubMed]

4. Dumont, M.; Beal, M.F. Neuroprotective strategies involving ROS in Alzheimer disease. Free Radic. Biol. Med. 2011, 51, 1014-1026. [CrossRef] [PubMed]

5. Hemmati-Dinarvand, M.; Valilo, M.; Kalantary-Charvadeh, A.; Sani, M.A.; Kargar, R.; Safari, H.; Samadi, N. Oxidative stress and Parkinson's disease: Conflict of oxidant-antioxidant systems. Neurosci. Lett. 2019, 709, 134296. [CrossRef]

6. Cosentino, G.; Plantamura, I.; Cataldo, A.; Iorio, M.V. MicroRNA and Oxidative Stress Interplay in the Context of Breast Cancer Pathogenesis. Int. J. Mol. Sci. 2019, 20, 5143. [CrossRef]

7. Gülçin, İ.; Şat, İ.G.; Beydemir, Ş.; Elmastaş, M.; Küfrevioğlu, Ö.İ. Comparison of antioxidant activity of clove (Eugenia caryophylata Thunb) buds and lavender (Lavandula stoechas L.). Food Chem. 2004, 87, 393-400. [CrossRef]

8. Qu, Y.; Li, C.; Zhang, C.; Zeng, R.; Fu, C. Optimization of infrared-assisted extraction of Bletilla striata polysaccharides based on response surface methodology and their antioxidant activities. Carbohydr. Polym. 2016, 148, 345-353. [CrossRef]

9. Peng, Q.; Li, M.; Xue, F.; Liu, H. Structure and immunobiological activity of a new polysaccharide from Bletilla striata. Carbohydr. Polym. 2014, 107, 119-123. [CrossRef] 
10. Chen, Z.; Cheng, L.; He, Y.; Wei, X. Extraction, characterization, utilization as wound dressing and drug delivery of Bletilla striata polysaccharide: A review. Int. J. Biol. Macromol. 2018, 120, 2076-2085. [CrossRef]

11. He, X.; Wang, X.; Fang, J.; Zhao, Z.; Huang, L.; Guo, H.; Zheng, X. Bletilla striata: Medicinal uses, phytochemistry and pharmacological activities. J. Ethnopharmacol. 2017, 195, 20-38. [CrossRef]

12. Niu, J.; Wang, S.; Wang, B.; Chen, L.; Zhao, G.; Liu, S.; Wang, S.; Wang, Z. Structure and anti-tumor activity of a polysaccharide from Bletilla ochracea Schltr. Int. J. Biol. Macromol. 2019. [CrossRef]

13. Le, X.D.; Nguyen, M.C.; Vu, D.H.; Pham, M.Q.; Pham, Q.L.; Nguyen, Q.T.; Nguyen, T.A.; Pham, V.T.; Bach, L.G.; Nguyen, T.V. Optimization of Microwave-Assisted Extraction of Total Phenolic and Total Flavonoid Contents from Fruits of Docynia indica (Wall.) Decne. Using Response Surface Methodology. Processes 2019, 7, 485. [CrossRef]

14. Hu, W.; Zhao, Y.; Yang, Y.; Zhang, H.; Ding, C.; Hu, C.; Zhou, L.; Zhang, Z.; Yuan, S.; Chen, Y. Microwave-assisted extraction, physicochemical characterization and bioactivity of polysaccharides from Camptotheca acuminata fruits. Int. J. Biol. Macromol. 2019, 133, 127-136. [CrossRef]

15. Xu, Z.; Wang, B.; Fu, L.; Wang, H.; Liu, J.; Zhou, L.; Yuan, M.; Ding, C. Optimization Extraction, Purification and Antioxidant Activities of Polysaccharides from Penthorum Chinense Pursh. Int. J. Food Eng. 2019, 15. [CrossRef]

16. Wang, D.; Li, C.; Fan, W.; Yi, T.; Wei, A.; Ma, Y. Hypoglycemic and hypolipidemic effects of a polysaccharide from Fructus Corni in streptozotocin-induced diabetic rats. Int. J. Biol. Macromol. 2019, 133, 420-427. [CrossRef] [PubMed]

17. Le, X.T.; Huynh, M.T.; Pham, T.N.; Than, V.T.; Toan, T.Q.; Bach, L.G.; Trung, N.Q. Optimization of Total Anthocyanin Content, Stability and Antioxidant Evaluation of the Anthocyanin Extract from Vietnamese Carissa Carandas L. Fruits. Processes 2019, 7, 468. [CrossRef]

18. Cui, C.; Lu, J.; Sun-Waterhouse, D.; Mu, L.; Sun, W.; Zhao, M.; Zhao, H. Polysaccharides from Laminaria japonica: Structural characteristics and antioxidant activity. LWT Food. Sci. Technol. 2016, 73, 602-608. [CrossRef]

19. Xiang, C.; Xu, Z.; Liu, J.; Li, T.; Yang, Z.; Ding, C. Quality, composition, and antioxidant activity of virgin olive oil from introduced varieties at Liangshan. LWT Food. Sci. Technol. 2017, 78, 226-234. [CrossRef]

20. Xu, Z.; Feng, S.; Qu, J.; Yuan, M.; Yang, R.; Zhou, L.; Chen, T.; Ding, C. The Effect of Extraction Methods on Preliminary Structural Properties and Antioxidant Activities of Polysaccharides from Lactarius vividus. Processes 2019, 7, 482. [CrossRef]

21. Xu, Z.; Wang, H.; Wang, B.; Fu, L.; Yuan, M.; Liu, J.; Zhou, L.; Ding, C. Characterization and antioxidant activities of polysaccharides from the leaves of Lilium lancifolium Thunb. Int. J. Biol. Macromol. 2016, 92, 148-155. [CrossRef] [PubMed]

22. Shang, H.; Wu, H.; Dong, X.; Shi, X.; Wang, X.; Tian, Y. Effects of different extraction methods on the properties and activities of polysaccharides from Medicago sativa L. and extraction condition optimization using response surface methodology. Process. Biochem. 2019, 82, 179-188. [CrossRef]

23. Wang, Y.; Wang, X.; Xiong, Y.; Fan, J.; Zheng, Z.; Li, Y.; Dong, L.; Zhao, Z. Extraction optimization, separation and antioxidant activity of Luffa cylindrica polysaccharides. Food. Bioprod. Process. 2019, 116, 98-104. [CrossRef]

24. Li, J.; Zhao, H.; Hu, X.; Shi, J.; Shao, D.; Jin, M. Antidiabetic effects of different polysaccharide fractions from Artemisia sphaerocephala Krasch seeds in db/db mice. Food. Hydrocolloid. 2019, 91, 1-9. [CrossRef]

25. Lu, Y.; Xu, L.; Cong, Y.; Song, G.; Han, J.; Wang, G.; Zhang, P.; Chen, K. Structural characteristics and anticancer/antioxidant activities of a novel polysaccharide from Trichoderma kanganensis. Carbohydr. Polym. 2019, 205, 63-71. [CrossRef]

26. Zhang, A.; Shen, Y.; Cen, M.; Hong, X.; Shao, Q.; Chen, Y.; Zheng, B. Polysaccharide and crocin contents, and antioxidant activity of saffron from different origins. Ind. Crop. Prod. 2019, 133, 111-117. [CrossRef]

27. Campestrini, L.H.; Rasera, G.B.; de Camargo, A.C.; Franchin, M.; Nani, B.D.; Rosalen, P.L.; Canniatti-Brazaca, S.G.; Biasoto, A.C.T.; Shahidi, F.; Alencar, S.M. Alkaline conditions better extract anti-inflammatory polysaccharides from winemaking by-products. Food. Res. Int. 2019. [CrossRef]

28. Zhu, X.-Y.; Mang, Y.-L.; Xie, J.; Wang, P.; Su, W.-K. Response surface optimization of mechanochemical-assisted extraction of flavonoids and terpene trilactones from Ginkgo leaves. Ind. Crop. Prod. 2011, 34, 1041-1052. [CrossRef] 
29. Liu, X.; Chen, Y.; Wu, L.; Wu, X.; Huang, Y.; Liu, B. Optimization of polysaccharides extraction from Dictyophora indusiata and determination of its antioxidant activity. Int. J. Biol. Macromol. 2017, 103, 175-181. [CrossRef]

30. Fu, L.; Yuan, J.; Huang, J.; Wang, H.; Wang, Q.; Xie, Z.; Li, Y.; Wang, T.; Feng, S.; Ding, C. Optimal extraction and antioxidant activities of flavonoids from Penthorum chinense Pursh. J. Food. Meas. Charact. 2019, 13, 2253-2264. [CrossRef]

31. Wang, W.; Li, X.; Bao, X.; Gao, L.; Tao, Y. Extraction of polysaccharides from black mulberry fruit and their effect on enhancing antioxidant activity. Int. J. Biol. Macromol. 2018, 120, 1420-1429. [CrossRef] [PubMed]

32. Parker, T.L.; Miller, S.A.; Myers, L.E.; Miguez, F.E.; Engeseth, N.J. Evaluation of synergistic antioxidant potential of complex mixtures using oxygen radical absorbance capacity (ORAC) and electron paramagnetic resonance (EPR). J. Agric. Food. Chem. 2010, 58, 209-217. [CrossRef]

33. Ghavi, P.P. The extraction process optimization of antioxidant polysaccharides from Marshmallow (Althaea officinalis L.) roots. Int. J. Biol. Macromol. 2015, 75, 51-57. [CrossRef] [PubMed]

34. Sridhar, K.; Charles, A.L. In vitro antioxidant activity of Kyoho grape extracts in DPPH and ABTS assays: Estimation methods for EC50 using advanced statistical programs. Food Chem. 2019, 275, 41-49. [CrossRef] [PubMed]

35. Hui, Y.; Jun-Li, H.; Chuang, W. Anti-oxidation and anti-aging activity of polysaccharide from Malus micromalus Makino fruit wine. Int. J. Biol. Macromol. 2019, 121, 1203-1212. [CrossRef] [PubMed]

36. Jiang, J.; Kong, F.; Li, N.; Zhang, D.; Yan, C.; Lv, H. Purification, structural characterization and in vitro antioxidant activity of a novel polysaccharide from Boshuzhi. Carbohydr. Polym. 2016, 147, 365-371. [CrossRef]

(C) 2020 by the authors. Licensee MDPI, Basel, Switzerland. This article is an open access article distributed under the terms and conditions of the Creative Commons Attribution (CC BY) license (http://creativecommons.org/licenses/by/4.0/). 